\title{
Gezondheidsverschillen vragen om persoonsgerichte, inte- grale zorg door eerstelijns- en publieke gezondheidszorg
}

\author{
Maria van den Muijsenbergh
}

Published online: 11 February 2019

(c) The Author(s) 2019

\begin{abstract}
Mensen met een lage opleiding, weinig inkomen of een migratieachtergrond hebben een slechtere somatische en psychische gezondheid dan anderen. Deze sociaaleconomische en etnische gezondheidsverschillen worden veroorzaakt door de wisselwerking tussen chronische ongunstige omstandigheden (persoonlijke zowel als sociale omgevingsfactoren) en het mede daardoor tekortschietende aanpassingsvermogen, vaak in combinatie met onvoldoende gezondheidsvaardigheden. Persoonsgerichte, integrale zorg besteedt actieve aandacht aan het hele verhaal van de patiënt en aan alle factoren die zijn gezondheid beïnvloeden. Dit zijn van oudsher kernelementen van de huisartsenzorg en leiden tot betere uitkomsten van zorg, ook bij laagopgeleide mensen en migranten. Geïntegreerd met publieke gezondheidszorg en het sociale domein kan huisartsenzorg op deze wijze bijdragen aan het terugdringen van gezondheidsachterstanden.
\end{abstract}

\section{Sociaaleconomische en etnische gezondheids-} verschillen

Onder sociaaleconomische gezondheidsverschillen verstaan we de systematische verschillen in gezondheid tussen mensen met een hoge en mensen met een lage maatschappelijke positie. Deze positie wordt in sterke mate bepaald door opleiding, inkomen en migratieachtergrond. De verschillen in levensverwachting tussen hoog- en laagopgeleiden in Nederland zijn groot: in de periode 2011-2014 bedroegen

Dit is een Bewerking van het artikel 'De huisarts maakt het verschil' in Bijblijven 2018, gebaseerd op de oratie 'Verschil moet er zijn', d.d. 8 maart 2018.

Prof.dr. M. van den Muijsenbergh ( $ه)$

Afdeling Eerstelijnsgeneeskunde, Radboudumc, Nijmegen, Nederland

Maria.vandenMuijsenbergh@radboudumc.nl deze 6,7 jaar bij mannen en 6 jaar bij vrouwen. De verschillen in gezonde levensjaren (de jaren in een als goed ervaren gezondheid) zijn nog veel groter: laagopgeleide mannen leefden in dezelfde periode 18,7 jaar korter in goede gezondheid dan hoogopgeleide mannen. Voor vrouwen was dit verschil 19 jaar [1]. Deze verschillen nemen nog niet af in Nederland [2].

Wereldwijd geldt: hoe lager op de sociale ladder, hoe hoger het risico op alle belangrijke doodsoorzaken, wel en niet leefstijlgerelateerd. Ook in Nederland zien we grote sociaaleconomische verschillen bij chronische aandoeningen. Mensen met alleen basisonderwijs hadden in 2016 bijvoorbeeld viermaal vaker diabetes mellitus type 2 en viermaal vaker COPD dan mensen met een hbo- of universitaire opleiding $[3,4]$.

Deze verschillen betreffen ook psychische en sociale problemen. Maar liefst $21 \%$ van de laagst opgeleide mensen voelt zich psychisch ongezond, vergeleken met $9 \%$ van de hoogst opgeleiden (cijfers over 2013) [5]. Eenzaamheid komt driemaal zo vaak voor onder laagopgeleiden als onder hoogopgeleiden [6] en dementie zien we meer onder laagopgeleiden en migranten [7].

Niet-westerse migranten hebben in het algemeen een slechtere gezondheid dan autochtone Nederlanders met dezelfde SES: zij hebben $22 \%$ meer last (gedefinieerd als jaren in ziekte doorgebracht) van chronische aandoeningen, terwijl ze over het algemeen juist minder roken [8]. Psychische problemen, zoals depressie en angststoornissen, komen bij hen ook vaker voor.

In de lokale wijkprofielen van de GGD kunnen we goed zien hoe in bepaalde wijken met een overwegend laagopgeleide of migrantenbevolking overgewicht, eenzaamheid en schulden veel vaker voorkomen dan in andere 'rijkere' wijken. Ook in huisartsenregistraties zien we de sociaaleconomische gezondheids- 
Tabel 1 Aantal geregistreerde diagnoses per 1.000 patiënten/inkomensgroep in 2013 [9]

\begin{tabular}{|l|c|c|}
\hline & $20 \%$ laagste inkomens & $20 \%$ hoogste inkomens \\
\hline psychische problemen & 249 & 137 \\
\hline diabetes & 69 & 40 \\
\hline sociale problemen & 55 & 37 \\
\hline
\end{tabular}

verschillen terug: bij mensen uit de $20 \%$ laagste inkomensgroep registreerden huisartsen in 2013 veel vaker diabetes, psychische problemen en sociale problemen (zie tab. 1).

Ook in zorggebruik en uitkomsten van de zorg zijn er sociaaleconomische en etnische verschillen. Mensen met een laag inkomen en niet-westerse migranten komen vaker bij de huisarts dan mensen met een hoog inkomen en autochtone Nederlanders, en juist minder vaak bij de fysiotherapeut en tandarts, en doen ook minder vaak mee aan bevolkingsonderzoek [9]. Migranten en laagopgeleide mensen hebben meer complicaties bij cardiovasculaire aandoeningen en diabetes [10], en slechtere uitkomsten van zorg bij kanker [11].

\section{Oorzaken van gezondheidsverschillen}

Hoe komt het dat mensen met een lage opleiding, laag inkomen of een migratieachtergrond een slechtere gezondheid hebben? Uiteraard ligt daar een combinatie van elkaar beïnvloedende factoren aan ten grondslag, die per persoon verschilt. Maar bijna altijd is sprake van langdurige blootstelling aan ongezonde omstandigheden in combinatie met (en vaak leidend tot) een tekortschietend vermogen om optimaal voor de gezondheid te zorgen, ofwel beperkte gezondheidsvaardigheden. Gezondheidsvaardigheden zijn de vaardigheden om aan gezondheid gerelateerde informatie te vergaren, te begrijpen en toe te passen om zo weloverwogen beslissingen te nemen over de gezondheid [12]. Deze vaardigheden zijn vanzelfsprekend lastiger voor mensen die niet goed kunnen lezen en schrijven of het gezondheidszorgsysteem in een land niet kennen. Maar ook door stress, een opeenstapeling van problemen of uitputting kan het (tijdelijk) moeilijk zijn om goed voor de eigen gezondheid te zorgen. Bijna $30 \%$ van alle Nederlanders hebben beperkte gezondheidsvaardigheden [12].

Die ongezonde omstandigheden kunnen een ongezonde leefstijl betreffen, maar ook sociale omgevingsfactoren, zoals de blootstelling aan fijnstof of geweld, gebrek aan groen, slechte huisvesting en dergelijke. Het verschil tussen mensen met een hoge en lage maatschappelijke status verdwijnt niet wanneer een riskante leefstijl, zoals roken, wordt verdisconteerd er is dus meer aan de hand. Vermoedelijk heeft het te maken met de wijze waarop subjectieve ervaringen onze biologie beïnvloeden: sociale status die negatief wordt gewaardeerd is ook negatief voor de gezond- heid. Wat in de geest gebeurt heeft een cruciale impact op wat in de rest van ons lijf gebeurt.

Chronische tegenslag (geweld, armoede, verlies van werk, seksisme, racisme) heeft schadelijke effecten op de gezondheid, door wat men 'allostatische overbelasting' noemt. Dan overstijgt een trauma of cumulatieve stress het vermogen van het lichaam om zich aan veranderde omstandigheden aan te passen (allostasis), en dit schaadt immunologische en hormonale functies, en leidt uiteindelijk tot ziekte, vroegtijdige veroudering en overlijden [13]. De psychoneuro-immunologie ontrafelt steeds meer de bijzondere interacties tussen immuunsysteem, autonoom zenuwstelsel en de subjectieve ervaring van het individu en schept zo steeds meer inzicht in de kracht van zowel positieve als negatieve psychische gesteldheid om het gezond functioneren van het menselijk lichaam te bevorderen of te ondermijnen. Zo bleek uit onderzoek van Tomasdottir et al. dat een chronisch gebrek aan zelfwaardering, welzijn of sociale contacten kan leiden tot allostatische overbelasting, waardoor de kans op multimorbiditeit groter wordt [14]. En uit ander onderzoek bleek een relatie te bestaan tussen chronische stress en het ontstaan van diabetes, in Nederland in het bijzonder ook bij vluchtelingen [15].

Bij migranten spelen naast sociaaleconomische omstandigheden ook andere factoren een rol: een taalbarrière en verschillen met het gezondheidszorgsysteem in het land van herkomst leiden vaak tot minder toegankelijke en minder effectieve zorg, maar bovendien vormen de migratiegeschiedenis en ervaren discriminatie extra bronnen van stress. Voor hypertensie en depressie is de relatie met ervaren discriminatie duidelijk aangetoond [16].

\section{Persoonsgerichte, integrale zorg levert gezond- heidswinst op}

Aangezien individuele ervaringen zo'n sterke invloed hebben op onze biologie en dus op onze gezondheid, is het belangrijk om als zorgverlener aandacht te besteden aan het levensverhaal van de patiënt, om persoonsgerichte zorg te leveren. Dit vereist oprechte aandacht, nieuwsgierigheid naar de ander, ook als die in opleiding, sociale status of interesse ver van je afstaat.

Zowel het vertellen van het levensverhaal als het verstaan ervan wordt bevorderd door een goede artspatiëntrelatie, die op haar beurt sterk gebaat is bij persoonlijke continuïteit. De positieve effecten van een goede arts-patiëntrelatie, van empathie en van persoonsgerichte communicatie zijn sinds lang bekend en gelden a fortiori voor patiënten in achterstandssituaties met complexe problematiek [17]. Patiënten met een lage sociaaleconomische status vinden het belangrijk dat ze zich gezien voelen door hulpverleners. De meest kwetsbare patiënten hebben zelden het gevoel gewaardeerd te worden, en misschien is het wel een van de krachtigste interventies die een arts 
Persoonsgerichte en populatiebewuste zorg in de praktijk

Concreet vertaald naar de dagelijkse praktijk betekent zo'n persoonsgerichte, populatiebewuste en integrale benadering dat de eerste lijn en publieke gezondheidszorg [19]:

1. kennis hebben van en rekening houden met sociale en culturele verschillen tussen mensen;

2. bij de patiënt of doelgroep nagaan wat voor hem of hen de betekenis is van ziekte en gezondheid, en hiermee rekening houden - de zorg is dan meer gericht op de persoonlijke doelen van de patiënt dan alleen op de ziekte (persoonsgerichte, doelgerichte zorg);

3. afgestemd zijn op de behoefte van de betreffende persoon of groep, in plaats van voor iedereen hetzelfde te bieden (persoonsgerichtheid en equity);

4. beschikbaar en bereikbaar zijn voor alle groepen mensen, zowel in fysieke, geografische, financiële als culturele zin. Dit betekent onder meer dat de organisatie van de praktijk en de communicatie zijn afgestemd op het taal- en opleidingsniveau van de patiënten;

5. inzicht hebben in de specifieke sociale determinanten (opleiding, inkomen, woonomgeving, migratieachtergrond) en de invloed daarvan op de gezondheid (populatiebewust);

6. samenwerken met andere sectoren binnen de zorg en op het gebied van wonen, werken en welzijn (integrale aanpak);

7. betrokken zijn bij activiteiten om de leefomgeving van hun populatie te verbeteren en niet wachten totdat mensen met klachten komen (populatiebewust en proactief), dus bijvoorbeeld gezondheidsbedreigende situaties in de wijk signaleren en kenbaar maken bij de hiervoor verantwoordelijke instanties, zoals de gemeente;

8. de burgers zo veel mogelijk betrekken in de besluitvorming (persoonsgerichte zorg) en in plannen om hun omgeving te verbeteren (empowerment).

kan bieden wanneer hij oprecht zijn positieve aandacht en waardering voor de patiënt laat blijken.

Persoonsgerichte zorg heeft direct positieve gevolgen voor de gezondheid en leidt tot toegenomen zelfredzaamheid, minder angst, pijn en depressie, minder verwijzingen of aanvullend onderzoek, en betere HbAlc bij diabetes en longfunctie bij COPD [17].

Wanneer we aandacht besteden aan alle problemen van de patiënt is dat niet alleen persoonsgerichte, maar ook integrale zorg. Integrale zorg richt zich op de preventie en behandeling van ziekmakende lichamelijke, psychische en maatschappelijke factoren van individuen en groepen (bijvoorbeeld in een wijk). Het gaat dan naast leefstijl, gezondheidsvaar- digheden en inkomen om de fysieke omgeving (de luchtkwaliteit, de mate waarin de omgeving uitnodigt tot beweging), de sociale omgeving (sociale relaties, veiligheid), maatschappelijke participatie (werk, opleiding) en de toegankelijkheid van de zorg en andere voorzieningen. Kennis en begrip van de omgeving bieden vaak de sleutel tot goede zorg voor het individu [18]. Goede (huisartsgeneeskundige) zorg is dus niet alleen persoonsgericht, maar ook populatiegericht. Zo blijken leefstijlinterventies het effectiefst als ze worden ondersteund door een gezondheidsbeleid gericht op de hele wijk of gemeenschap [19]. Dit vereist een public health-blik van huisartsen, zodat deze alert zijn op gezondheidsrisico's in hun wijk of in de leefomgeving van hun patiënten, en hier zo nodig aandacht voor vragen van de publieke gezondheidszorg of andere instanties. Andersom is het voor de publieke gezondheidszorg van belang om aandacht te besteden aan die persoonlijke verschillen tussen mensen: geen one-size-fits-all-benadering voor gezondheidsbevorderende interventies, maar op maat gemaakt voor de doelgroep die men wil bereiken. Pharos heeft voor het Centrum Gezond Leven op een rij gezet waaraan interventies dienen te voldoen om lage SES-groepen en migranten te bereiken [20]. Voor een dergelijke brede benadering is samenwerking noodzakelijk, binnen de eerste lijn, met publieke gezondheid en het sociale domein.

\section{Tot slot}

De hier beschreven persoonsgerichte integrale benadering lijkt het meest kansrijk om structureel sociaaleconomische en etnische gezondheidsachterstanden te verminderen, mits zij steeds is afgestemd op de doelen die de beoogde burgers zelf stellen.

Eerstelijnsprofessionals kunnen samen met de publieke gezondheidszorg een sleutelrol vervullen bij het overbruggen van de afstand tussen de individuele behandeling van ziekten en de wijk- en populatiegerichte gezondheidsbevordering. Dit wordt ook door het Nederlands Huisartsen Genootschap (NHG) en de Landelijke Huisartsen Vereniging (LHV) expliciet als uitgangspunt geformuleerd voor de huisartsenzorg in de komende jaren [21].

Op termijn valt hiervan veel winst te verwachten bij de bestrijding van gezondheidsachterstanden.

Open Access This article is distributed under the terms of the Creative Commons Attribution 4.0 International License (http://creativecommons.org/licenses/by/4.0/), which permits unrestricted use, distribution, and reproduction in any medium, provided you give appropriate credit to the original author(s) and the source, provide a link to the Creative Commons license, and indicate if changes were made.

\section{Literatuur}

1. Centraal Bureau voor de Statistiek. Gezonde levensverwachting naar opleidingsniveau. Den Haag: Centraal 
Bureau voor de Statistiek; 2016. http://statline.cbs.nl/ Statweb/publication/?DM=SLNL\&PA=71885ned\&D1 $=0$ $4 \& \mathrm{D} 2=\mathrm{a} \& \mathrm{D} 3=0,14 \& \mathrm{D} 4=\mathrm{a} \& \mathrm{D} 5=0 \& \mathrm{D} 6=\mathrm{l} \& \mathrm{VW}=\mathrm{T}$.

2. Wetenschappelijke Raad voor het Regeringsbeleid WRR. Van verschil naar potentieel, een realistisch perspectief op sociaaleconomische gezondheidsverschillen. Den Haag: WRR;2018.

3. Centraal Bureau voor de Statistiek. Gezondheid en zorggebruik; persoonskenmerken; diabetes. Den Haag: Centraal Bureau voor de Statistiek; 2018. http://statline.cbs.nl/ Statweb/publication/?DM=SLNL\&PA=83005NED\&D1=3$5 \& \mathrm{D} 2=\mathrm{a} \& \mathrm{D} 3=0 \& \mathrm{D} 4=\mathrm{l} \& \mathrm{VW}=\mathrm{T}$.

4. Boerdam A, Knoops K. Bevolkingstrends: astma en COPD in beeld. Den Haag: Centraal Bureau voor de Statistiek; 2016. https://www.cbs.nl/nl-nl/achtergrond/2016/ 19/bevolkingstrends-astma-en-copd-in-beeld.

5. Centraal Bureau voor de Statistiek. Gezondheid, aandoeningen, beperkingen; persoonskenmerken. Den Haag: Centraal Bureau voor de Statistiek; 2015. http://statline. cbs.nl/Statweb/publication/?DM=SLNL\&PA=81173NED\& $\mathrm{D} 1=41 \& \mathrm{D} 2=0-20,34-38 \& \mathrm{D} 3=0 \& \mathrm{D} 4=\mathrm{l} \& \mathrm{VW}=\mathrm{T}$.

6. Beuningen J van, Witt S de. Eenzaamheid in Nederland. Den Haag: Centraal Bureau voor de Statistiek; 2016. https://www.cbs.nl/nl-nl/achtergrond/2016/38/ eenzaamheid-in-nederland.

7. Parlevliet JL, Uysal-Bozkir O, Goudsmit M. Prevalence of mild cognitive impairment and dementia in older nonwestern immigrants in the Netherlands: a cross-sectional study. Int J Geriatr Psychiatry. 2016;21:1040-9.

8. Kunst AE, Lamkaddem M, Mackenbach JP, et al. Overzicht en evaluatie van resultaten van wetenschappelijk onderzoek naar etnische verschillen in gezondheid, gezondheidsrisico's en zorggebruik in Nederland. Rotterdam, Utrecht: Erasmus MC, NIVEL; 2008.

9. Donker GA. NIVEL Zorgregistraties eerste lijn. Peilstations 2013. Utrecht: NIVEL; 2014

10. Elissen AMJ, Hertroijs DFL, Schaper NC, et al. Differences in biopsychosocial profiles of diabetes patients by level of glycaemic control and health-related quality of life: The MaastrichtStudy. PLoS ONE. 2017;12(7):e182053.

11. Aarts M. Socioeconomic determinants of cancer risk, detection, and outcomein the Netherlands since 1990. Rotterdam: Erasmus University Rotterdam;2012. Proefschrift.

12. Rademakers J. Kennissynthese: gezondheidsvaardigheden: niet voor iedereen vanzelfsprekend. Utrecht: NIVEL; 2014.

13. McEwen B. Protective and damaging effects of stress mediators. NEnglJ Med. 1998;338(3):171-9.

14. Tomasdottir M, Sigurdsson J, Petursson H, et al. Does 'existential unease' predict adult multimorbidity? BMJ Open. 2016;6(11):e12602.

15. Agyemang C, Goosen S, Anujuo K, et al. Relationship between post-traumatic stress disorder and diabetes among 105,180 asylum seekers in the Netherlands. Eur J Public Health. 2012;22(5):658-62.

16. Lamkaddem M, Essink-Bot M-L, Devillé W, et al. Perceived discrimination outside health care settings and health care utilization of Turkish and Moroccan GP patients in the Netherlands. Eur J Public Health. 2012;22(4):473-8.

17. Stewart M, Brown JB, Donner A, et al. The impact of patient-centered care on outcomes. J Fam Pract. 2000;49(9):796-804.

18. Maeseneer J de, Weel C van, Daeren L, et al. From 'patient' to 'person' to 'people': the need for integrated, peoplecentered healthcare. Int J Pers Cent Med. 2012;2(3):601-14.

19. Muijsenbergh $M$ van den, Hemke F. Aanpak van gezondheidsverschillen. In: Muijsenbergh M van den, Oosterberg E. Huisartsenzorg voor laaggeletterden, migranten en sociaal kwetsbaren. Utrecht: NHG, Pharos; 2016. pag. 59-60.

20. Been $M$ de, Muijsenbergh $M$ van den, Duijnhoven $T$. Gezondheid en kwaliteit van zorg voor iedereen. Wat maakt het verschil? Utrecht: Pharos; 2018. https:// www.loketgezondleven.nl/sites/default/files/PHAROS $\% 20$ Gezondheid\%20en\%20kwaliteit\%20van\%20zorg.pdf.

21. NHG/LHV. Toekomstvisie huisartsenzorg 2022. Utrecht: NHG, LHV; 2012. 